\title{
Starch analysis using hydrodynamic chromatography with a mixed-bed particle column
}

\author{
R.P. Dias ${ }^{\mathrm{a}, \mathrm{b}, 1}$, C.S. Fernandes ${ }^{\mathrm{c}, 2}$, M. Mota $^{\mathrm{a}, *}, \mathrm{~J}$ Teixeira ${ }^{\mathrm{a}}$, A. Yelshin ${ }^{\mathrm{a}}$ \\ ${ }^{a}$ Institute of Biotechnology and Bioengineering, IBB, Centro de Eng. Biológica, University of Minho, Campus de Gualtar, 4710-057 Braga, Portugal \\ ${ }^{\mathrm{b}}$ Departamento de Tecnologia Química e Biológica, Escola Superior de Tecnologia e de Gestão, Instituto Politécnico de Bragança, Campus de Santa Apolónia, \\ Apartado 134, 5301-857 Bragança, Portugal

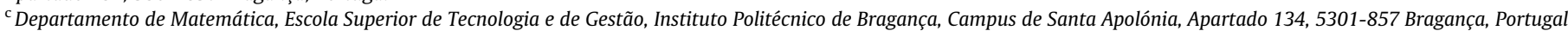

\section{A R T I C L E I N F O}

\section{Article history:}

Received 28 February 2008

Received in revised form 5 May 2008

Accepted 6 May 2008

Available online 13 May 2008

\section{Keywords:}

HDC

Starch analysis

Temperature

Packing

Glass beads

\begin{abstract}
A B S T R A C T
Columns packed with commercial glass beads 5 and $19 \mu \mathrm{m}$ average size and a mixture of both (0.7 volume fraction of large particles) were used to analyse starch composition by hydrodynamic chromatography (HDC), applying water as mobile phase. To obviate retrogradation, experiments were carried out at column temperatures of 15 and $3{ }^{\circ} \mathrm{C}$ and several types of starch were assayed. In what concerns amylopectin and amylose separation, a better resolution and a lower pressure drop were obtained for the mixed binary packing when compared with the packing containing uniform $5 \mu \mathrm{m}$ glass beads. A more efficient cooling of the mobile phase was also obtained with the mixed packing, which was determinant for improving resolution. For the Hylon VII starch the relative retention times (RRT) were 0.777 and 0.964 for amylopectin and amylose, respectively, while for the Tapioca starch the obtained RRTs were 0.799 and 0.923 . Application of unbound glass beads as column packing not only might reduce equipment and running costs in preparative scale separations, but also proved to be useful as a fast and reliable method to monitor the amylose and amylopectin content of starch samples of different sources.
\end{abstract}

(c) 2008 Elsevier Ltd. All rights reserved.

\section{Introduction}

Analysis of starch components amylose and amylopectin is conventionally carried out by high-performance size-exclusion chromatography (HPSEC) (Henshall, 2001; Kobayashi, Schwartz, \& Lineback, 1985). Microparticulate sorbents with average particle diameter between 5 and $13 \mu \mathrm{m}$ are used often in pre-packed columns of length $25-30 \mathrm{~cm}$ and of $4-8 \mathrm{~mm}$ internal diameter (I.D.) (Churms, 1996). Working temperature normally varies between room temperature and $60^{\circ} \mathrm{C}$. Amylopectin is eluted at the void volume of the column, whereas amylose is eluted later on, due to partitioning between the gel particles. In some cases other materials were reported to elute with volumes between those of amylopectin and amylose (Eliasson, 2004). The limitation of SEC is the high cost of the column packing especially at preparative scale processes (Vorwerg, Radosta, \& Leibnitz, 2002).

Equipment costs can be substantially reduced with the application of hydrodynamic chromatography. Klavons, Dintzis, and Millard (1997) used $25 \times 1-\mathrm{cm}$ columns filled with solid particles of $5-15 \mu \mathrm{m}$ diameter (average diameter was estimated to be

\footnotetext{
* Corresponding author. Tel.: +351 253604405; fax: +351253678986.

E-mail address: MMota@reitoria.uminho.pt (M. Mota).

1 Tel.: +351 273303150; fax: +351273313051.

2 Tel.: +351 273303127; fax: +351 273313051.
}

$10 \mu \mathrm{m})$. Columns were maintained at $60^{\circ} \mathrm{C}$ and the flow rates stayed in the range $0.1-0.5 \mathrm{ml} / \mathrm{min}$.

If the retention factor of the column $k=\left(t_{R}-t_{\mathrm{M}}\right) / t_{\mathrm{M}}$, where $t_{\mathrm{R}}$ and $t_{\mathrm{M}}$ are the retention times of retained and un-retained solutes, respectively, is represented as $k=t_{\mathrm{R}} / t_{\mathrm{M}}-1=\mathrm{RRT}-1$ (being $\mathrm{RRT}=t_{\mathrm{R}} / t_{\mathrm{M}}$ a relative retention time), then the comparison between HPSEC RRT and HDC RRT $=t / t_{\mathrm{M}}$ can be made $t$ is the retention time of the hydrodynamic sensitive solute). The comparison of the amylopectin and amylose RRT in the eluted liquid at HPSEC (Vorwerg et al., 2002; Yoo \& Jane, 2002) with the HDC RRT shows that similar values are obtained RRT $>0.736$ ). This suggests that HDC can be used to separate amylose and amylopectin as efficiently as HPSEC.

Hydrodynamic chromatography RRT depends on the ratio between the macromolecule size and the pore size. In turn, the macromolecule size is related to its conformational state that depends on the solute temperature. Based on this behaviour, it is possible to control macromolecular properties by controlling temperature. When the starch solution temperature is decreased, the amylopectin macromolecules flexibility is reduced while the amylose keeps its flexible macromolecular structure (Collado \& Corke, 2003; Galinsky \& Burchard, 1997).

The main endothermic transition associated with melting of the crystalline part of the starch granule followed by a helix-coil transition in amylopectin occurs over the temperature range 
319-333 K (Randzio, Flis-Kabulska, \& Grolier, 2003). The molecules of amylopectin have highly oblate ellipsoidal shape and are about $10-15 \mathrm{~nm}$ in diameter and 200-400 nm long (Durrani \& Donald, 2000; Randzio et al., 2003; Yang et al., 2006). Therefore, low temperature allows avoiding the hydrogen bond breakdown, thereby preserving the amylopectin structure (Tako \& Hizukuri, 2000).

In turn, amylose chains can coil into double helices and become insoluble in cold water. If a concentrated aqueous amylose solution is cooled to room temperature or below there is a rapid precipitation/phase separation process. The clear amylose solution rapidly becomes opaque indicating the formation of polymer aggregates. The aggregation rate in aqueous $0.2-5.0 \%$ solutions and the physical form of aggregated material have been studied as a function of chain length (Gidley \& Bulpin, 1989). Hence, as the present investigation was performed with a cooling rate above $5 \% \mathrm{~min}$, we can expect that fast cooling may prevent the formation of amylose aggregates of a size sufficient for precipitation.

Therefore, if the residence time of the sample in the chromatographic column is in the range 2-3 min, the amylopectin structure will be preserved whereas for amylose the retrogradation effect will be minimised (Farhat \& Blanshard, 2001).

The aim of this work is to define the best conditions for the efficient separation of amylose from amylopectin by HDC using commercial grade glass beads as packing material. The required column cooling length was estimated and the separation of amylopectin and amylose in different types of starch was evaluated.

\section{Experimental equipment and conditions}

The chromatographic system consists of an HPLC pump PU-1580 from Jasco (Tokyo, Japan) operated at a flow rate of $0.5 \mathrm{ml} / \mathrm{min}$, column, and a refractive index detector RI-2031 from Jasco including a PID temperature control and a cell of capacity $10 \mu \mathrm{l}$. The detector signal was monitored using a recorder PeakSimple 203 and integrator PeakSimple 2000 from SRI Instruments (CA, USA).

The flow velocity of $0.5 \mathrm{ml} / \mathrm{min}$ and a particle bed size of 5$19 \mu \mathrm{m}$ used in the present experimentation are conventional values usually applied in SEC or HPSEC chromatographic systems for starch analysis (see mentioned above references) therefore preventing a shear induced macromolecule degradation.

Three stainless steel columns $200 \times 4.6 \mathrm{~mm}$ I.D. from Grom Analytik (Rottenburg-Hailfingen, Germany) packed by the company with soda lime non-porous glass beads from Potters Ballotini (Saint-Pourcain-sur-Sioule, France) were used. Two mono-size columns were, respectively, packed with glass beads with average size $5 \mu \mathrm{m}$ (Spheriglass 5000) and $19 \mu \mathrm{m}$ (Spheriglass 3000). The third column was packed with a mixture of 5 and $19 \mu \mathrm{m}$ glass beads. The mixture composition was prepared according to Dias, Teixeira, Mota, and Yelshin (2004a) and contains 70\% of $19 \mu \mathrm{m}$ beads and $30 \%$ of $5 \mu \mathrm{m}$. The average particle size in the mixture was estimated as $10.3 \mu \mathrm{m}$. The backpressure ratio of mono$(5 \mu \mathrm{m})$ and binary packing column was $\sim 1.6$.

Experiments were performed keeping the column at tap-water temperature $\left(15^{\circ} \mathrm{C}\right)$ and at $3{ }^{\circ} \mathrm{C}$. To achieve a column temperature of $3^{\circ} \mathrm{C}$ the column was immersed and stabilised in a water bath containing crushed ice. A steady state temperature profile inside the columns was controlled by the HPLC pump backpressure which attained a constant value. Additional tests at $35^{\circ} \mathrm{C}$ did not show results different from that obtained at $15^{\circ} \mathrm{C}$ and therefore are not included in Section 3.

Water was used as the mobile phase and solvent. Distillate water was purified in the system Easypure LF D7382-33 from Barnsted (Dubuque, USA) and then degassed using magnetic stirring under vacuum. The mobile phase temperature before application was kept at $15^{\circ} \mathrm{C}$.
The following solutes were used in experiments. Sucrose from Merck (Darmstadt, Germany) was used as the infinite small size marker in HDC experiments that eluted with a retention time $t_{\mathrm{M}}$. Starches Novation 2600, Tapioca starch, and Hylon VII from $\mathrm{Na-}$ tional Starch \& Chemical (Manchester, UK) were purified as described by Han and Lim (2004). Hylon VII contains from $66 \%$ to 70\% amylose (Błaszczak, Fornal, Valverde, \& Garrido, 2005; Fang et al., 2005; Matveev et al., 2001; Nakazawa \& Wang, 2003); tapioca starch contains 17-23\% amylose (Nakazawa \& Wang, 2003; Suknark, Phillips, \& Chinnan, 1997) and Novation 2600 contains, according to the suppliers, more than $99 \%$ of amylopectin.

About $0.1 \mathrm{~g}$ of the purified starches, and $0.025 \mathrm{~g}$ of Amylose A-0512, from Sigma-Aldrich (St. Louis, USA) were dissolved in $100 \mathrm{ml}$ of water, using an autoclave Avtester-E 75 I DRY from Selecta (Barcelona, Spain) during $40 \mathrm{~min}$ at $134^{\circ} \mathrm{C}$ (Han, BeMiller, Hamaker, \& Lim, 2003; Hanselmann, Burchard, Ehrat, \& Widmer, 1996). Autoclaved samples were centrifuged in a 2-4 centrifuge from SIGMA (Osterod am Harz, Germany) at $2000 \mathrm{~g}$ during $10 \mathrm{~min}$. The supernatant was filtered using a square wire cloth from Haver \& Boecker (Oelde, Germany) with aperture width $1 \mu \mathrm{m}$. Within a period of a few minutes after filtration, $20 \mu \mathrm{l}$ of the prepared samples were used in HDC experiments with the help of an injector 7725i from Rheodyne (CA, USA).

\section{Results and discussion}

\subsection{Determination of column cooling length}

Estimation of the column packing length required for a reduction of the sample temperature from room temperature (assumed to be $15^{\circ} \mathrm{C}$ ) to the bath temperature of $3{ }^{\circ} \mathrm{C}$, was performed using the finite-element computational fluid dynamics software POLYFLOW $^{\circledR}$. For this purpose, the temperature profile of the mobile phase non-isothermal laminar flow inside the chromatographic column was simulated by a two dimensional (2 D) model that has been proved to present good results (Billen, Gzil, Vervoort, Baron, \& Desmet, 2005; Kuwahara, Shirota, \& Nakayama, 2001).

Previous works demonstrated the advantage of a packing formed by a binary mixture of particles of different size at the region of minimum porosity $x_{D} \sim 0.7$ ( $x_{D}$ corresponds to the large $D$ size particle volume fraction in the mixture) over the mono-size packing (Dias, Fernandes, Mota, Teixeira, \& Yelshin, 2007; Dias, Teixeira, Mota, \& Yelshin, 2004b; Mota, Teixeira, \& Yelshin, 2001). Therefore, the simulation was performed for two cases: (1) a packing formed by mono-size particles of dimension $d$; and (2) a binary packing obtained from the mixture of large, $D$, and small, $d$, size particles at $x_{D}=0.7$.

A mono-size packing geometry (Fig. 1a), similar to the one presented by Kuwahara et al. (2001) was extended to the binary packing (Fig. 1b). The binary packing 2D geometry contains square shaped particles of size $d$ and $D$, and has a length $L=3.8 \mathrm{~mm}$ and a width $b=2.9 \mathrm{~mm}$. The same width was used on the mono-size packing geometry, but, in this case, the length was $L=4.25 \mathrm{~mm}$.

Calculated porosities of mono-size and binary packings $(0.415$ and 0.284 , respectively) (see Fig. 1), approached the experimental values for mono-size glass beads packing and a binary packing formed by a mixture of glass beads with size ratio $\delta=d / D=0.333$ / $1.179=0.282$ at $x_{D}=0.7$ (Dias et al., 2004b; Dias et al., 2007; Mota et al., 2001). This particle size ratio is close to the one used in the experiments below with the binary packing, $\delta=0.263$.

For comparison, additional simulation was performed for a cylindrical duct with I.D. $4.6 \mathrm{~mm}$ representing the empty chromatographic column used in the experimental part of this work.

The mesh used in the simulations (excepting for the cylindrical duct) was a regular structured grid of quadrilateral elements. For 
a

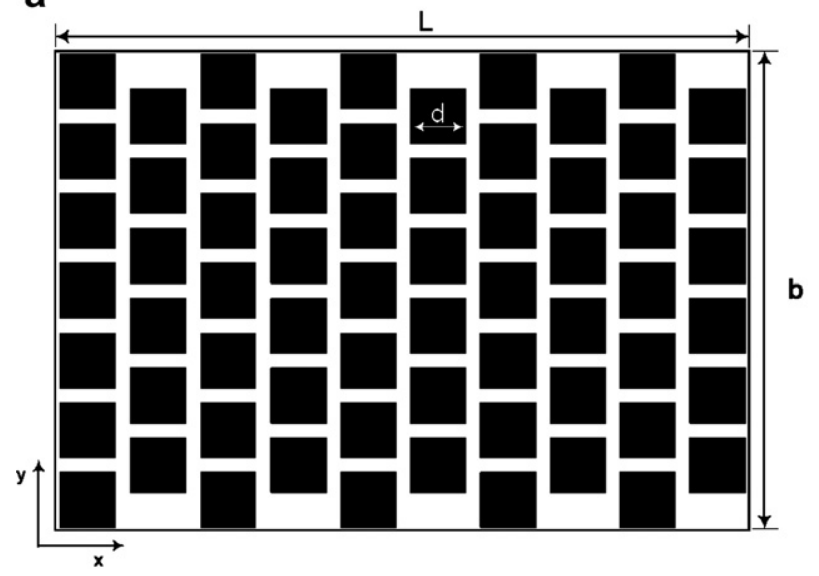

b

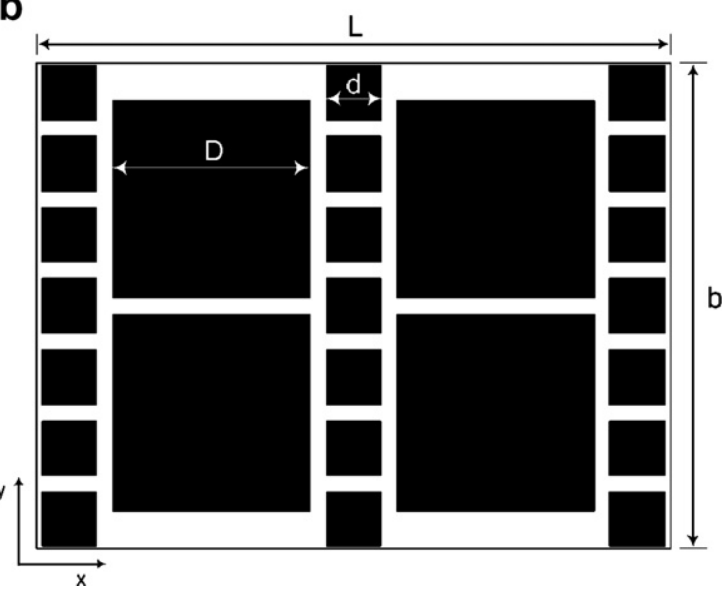

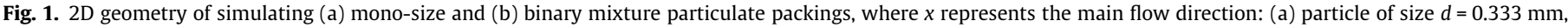
length $L=4.25 \mathrm{~mm}$; (b) particle of size $d=0.333$ and $D=1.179 \mathrm{~mm}$, length $L=3.8 \mathrm{~mm}$.

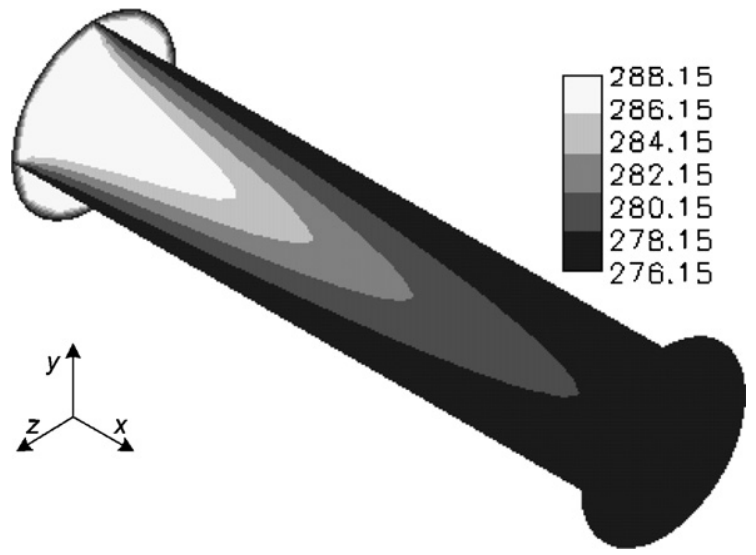

Fig. 2. Temperature profile in a cylindrical duct with dimensions $20 \times 4.6 \mathrm{~mm}$ I.D.

the cylindrical duct an unstructured mesh was used comprising tetrahedral, hexahedral and pyramidal elements. The size of the elements was fixed after a grid independency test.

The apparent linear flow velocity in the simulations was assumed to be $5 \times 10^{-4} \mathrm{~m} / \mathrm{s}$ for all geometries. This flow velocity corresponds to the volumetric flow velocity $0.5 \mathrm{ml} / \mathrm{min}$ in the cylindrical duct or chromatographic column with $4.6 \mathrm{~mm}$ I.D. used in the HDC experiments. A non-slipping condition at the channels wall and surface of the particles at a laminar flow regime was assumed.

The following temperatures were assumed in simulations: inlet temperature $15{ }^{\circ} \mathrm{C}$, wall temperature constant and equal to $3^{\circ} \mathrm{C}$. In

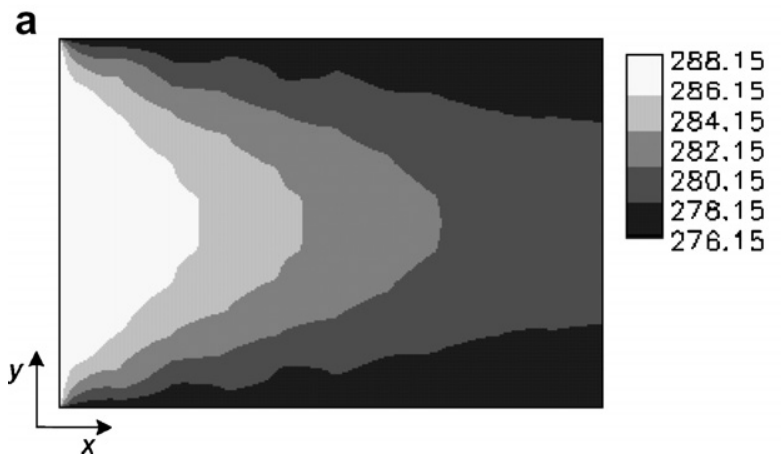

all simulations, water was used as the liquid phase (water physical properties at $9{ }^{\circ} \mathrm{C}$ were assumed throughout all the simulations).

Simulations with POLYFLOW ${ }^{\circledR}$ software were performed using a Dell Workstation PWS530 with 1GB of RAM and results are presented in Figs. 2 and 3.

The numerically estimated temperature profile $\left({ }^{\circ} \mathrm{K}\right)$ in the empty column immersed in the water bath at $3{ }^{\circ} \mathrm{C}$ is shown in Fig. 2. For the $0.5 \mathrm{ml} / \mathrm{min}$ flow rate and inlet water temperature of $15^{\circ} \mathrm{C}$, the temperature becomes close to $3^{\circ} \mathrm{C}$ (or $276.15 \mathrm{~K}$ as simulated) at $20 \mathrm{~mm}$ from the inlet and flow approaches isothermal. Obtained result means that for a $200-\mathrm{mm}$ column, which was the one used in this work, the non-isothermal flow occupies only $10 \%$ of the total column length. Furthermore (Dias et al., 2007), as is shown in Fig. 3, heat transfer will be improved with a column filled with a binary packing.

Comparing temperature distribution in mono-size packing (Fig. 3a), and binary packing (Fig. 3b), it is clear that binary packing heat exchange characteristics are better and that isothermal flow condition is attained after less than $3.8 \mathrm{~mm}$ from the inlet.

Besides this advantage, in the region of the particle size ratio $0.1<\delta<1.0$ and $x_{D} \sim 0.7$ the permeability of the binary bed is maximum (Dias et al., 2007).

These simulations validate the starch separation method based on the injection of the sample at room temperature into a cooled column.

\subsection{Starch separation}

Under the chromatographic conditions described in Section 2, the obtained chromatograms are shown in Figs. 4 and 5, where

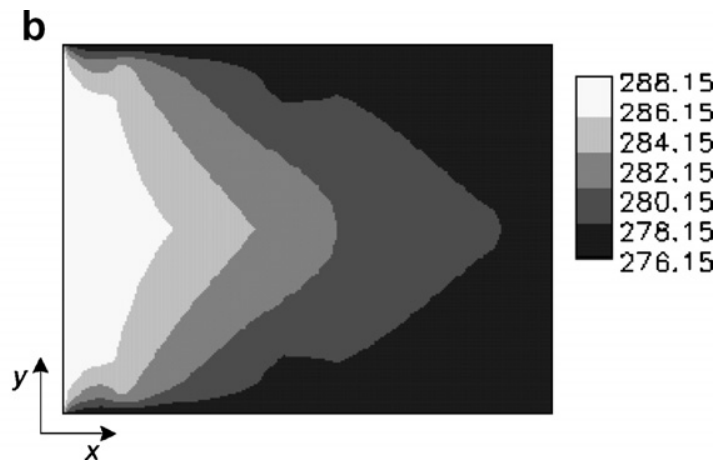

Fig. 3. Simulated temperature profile distribution in the mono-size packing, $L=4.25 \mathrm{~mm}$ (a) and binary packing, $L=3.8 \mathrm{~mm}$ (b). For dilates see Fig. 1 . 

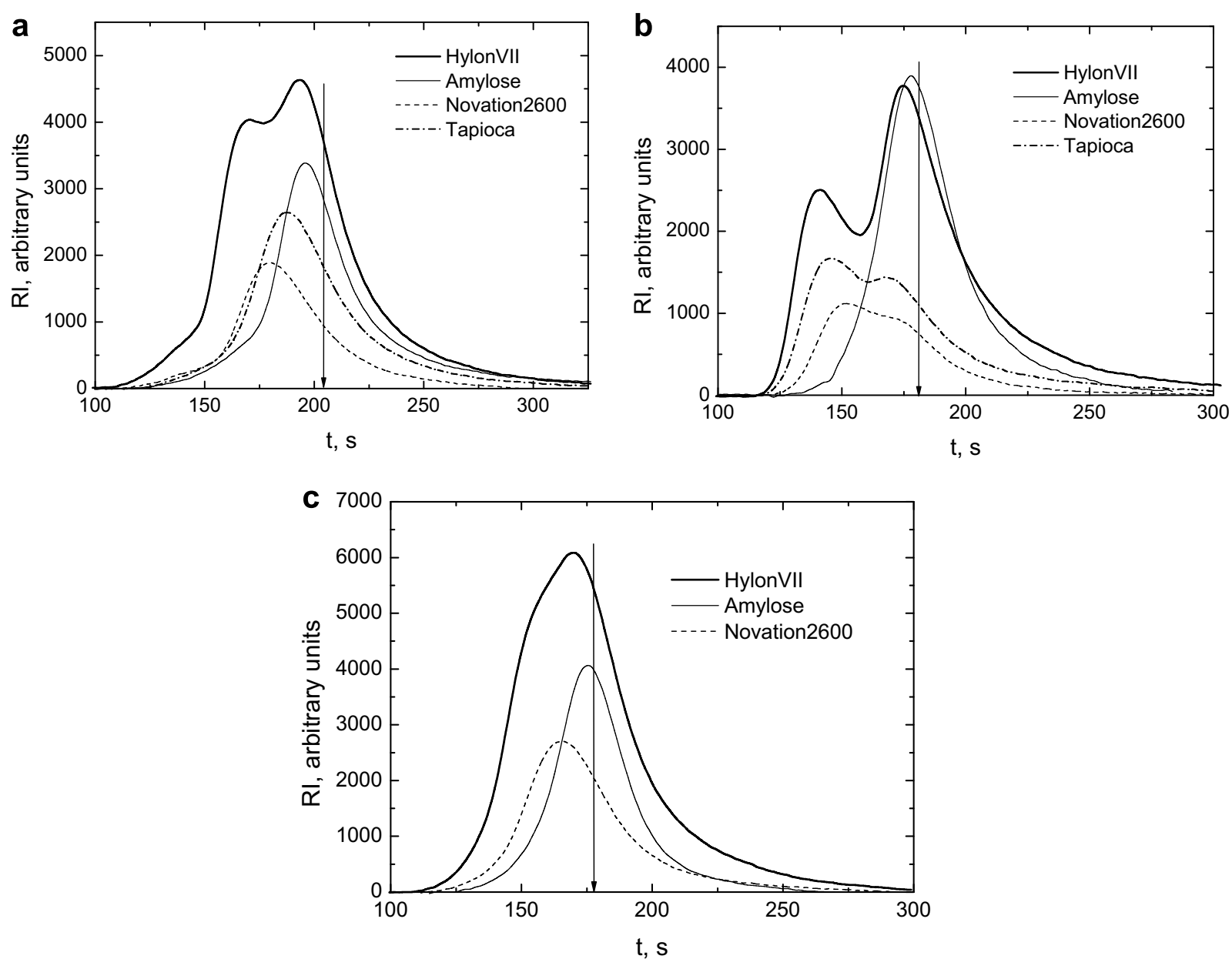

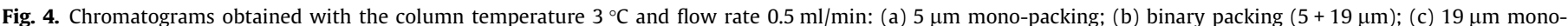
packing.

the arrow represents the retention time corresponding to the maximum value of the sucrose peak $t_{\mathrm{M}}$.

Results of starch separation at $3{ }^{\circ} \mathrm{C}$ are shown in Fig. 4. The cooling period within the column packing (see Fig. 3 ) was short with high cooling rate $\left(\sim 12^{\circ} / \mathrm{min}\right)$. Short and fast cooling procedure helps keeping amylose aggregation in lag(nucleation)-phase when their size is small for precipitation. Application of pure amylose A-0512 in experiments (Fig. 4) showed that there is no significant difference in the peak shape of amylose. Using Novation 2600 ( $~ 99 \%$ amylopectin) allows to identify the amylopectin peak. Furthermore, as shown below, binary peak system analysis (Fig. 4b) by means of multi-peak Gaussian distribution analysis leads to an amylopectin-amylose composition very close to the one used as inlet solution.

Based on data for pure amylose and amylopectin, we can identify the first peak as the amylopectin and the second as the amylose, (Fig. 4b). The best results were achieved on the mixed packing (Fig. 4b), where, for Hylon VII, the relative retention times for amylopectin and amylose were RRT $=0.777$ and 0.964 , respectively. For the $5 \mu \mathrm{m}$ packing the corresponding values were, respectively, $\mathrm{RRT}=0.836$ and 0.949 . The amount of amylose was calculated by performing the data acquisition software PeakSimple 2000 for PeakSimple 203 recorder and integrator from SRI Instruments (CA, USA). The calculated amount of amylose in Hylon VII was $67.7 \%$ (for the $5 \mu \mathrm{m}$ packing) and $69.9 \%$ (mixed bed) that is within the range of reported values for Hylon VII composition (Błaszczak et al., 2005; Fang et al., 2005; Matveev et al., 2001; Nakazawa \& Wang, 2003).
Moreover, the mixed column was able to separate amylose and amylopectin in Tapioca starch, with a calculated amylose amount of $22.7 \%$, a composition that corresponds to value of the inlet solution composition. For Tapioca starch the relative retention times in the mixed column for amylopectin and amylose were determined as $\mathrm{RRT}=0.799$ and 0.923 , respectively.

The botanical source of starch and dissolution process influences the size of amylose and amylopectin molecules (Bello-Pérez, Roger, Baud, \& Colonna, 1998; Yoo \& Jane, 2002). Dispersing different starches in water, Yoo and Jane (2002) determined that the gyration radius from amylopectin in Tapioca starch was lower than the gyration radius from amylopectin in the maize starch Hylon VII, both supplied from National Starch \& Chemical. The amylose from Hylon VII has been reported to have the smallest molecular weight among numerous starches of different botanical origin.

According to HDC theory, larger macromolecules have a smaller RRT. Therefore, results presented in Fig. 4b may be explained by the relative sizes of amylose in the two types of starch tested: for the binary packing, amylopectin and amylose RRT are, respectively, lower and higher than the corresponding values for Tapioca starch. For this reason, for the binary packing, the resolution observed with Hylon VII was higher than with Tapioca starch (see Fig. 4b).

The observed dispersion of Novation 2600 peak (Fig. 4b), might be attributed to the variety of amylopectin polymerisation degree giving consequently different responses to cooling. The HDC efficiency decreases when the large size particles $(19 \mu \mathrm{m})$ (Fig. 4), 

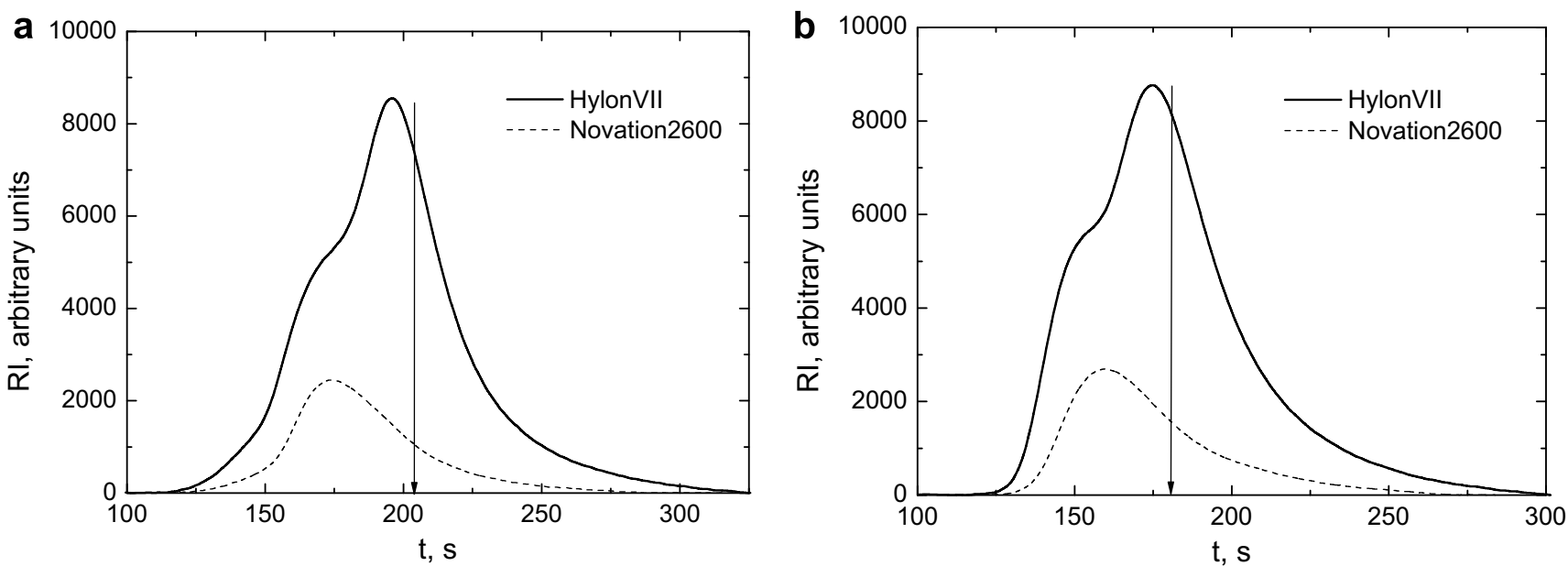

Fig. 5. Chromatograms obtained with a column temperature $15^{\circ} \mathrm{C}$ and flow rate $0.5 \mathrm{ml} / \mathrm{min}$ : (a) $5 \mu \mathrm{m}$ mono-packing; (b) binary packing ( $\left.5+19 \mu \mathrm{m}\right)$.

and a column temperature of $15^{\circ} \mathrm{C}$, are used both for monosize (Fig. 5a), and for mixed packing (Fig. 5b). Increasing the temperature up to $35^{\circ} \mathrm{C}$ did not improve separation. Klavons et al. (1997) performed HDC of waxy maize starch at $60^{\circ} \mathrm{C}$ and obtained only one peak.

According to HDC theory, larger macromolecules have a smaller RRT in pores of similar size. Comparing Fig. 4a (particle of $5 \mu \mathrm{m}$ ) and $4 \mathrm{~b}(5+19 \mu \mathrm{m})$ additional effects can be pointed out. Firstly, the reduced temperature allows improving amylopectin (AP)amylose (AM) separation, which might be attributed by semi-rigid shaped form of AP macromolecules. Hydrodynamic radius of AP molecule becomes larger due to prolate conformation and yields better separation AP and AM molecules with intermediate molecular weight. Nevertheless, increasing the hydrodynamic radius of the AP molecule is not sufficient to separate Tapioca starch in the case of the mono-packing column (see Fig. 4a). Therefore, the pore topology is a factor that must participate in HDC process. More complex pore topology exhibited in binary packing affects the flow velocity of shaped semi-rigid AP macromolecules in a manner similar to the one described by Mota, Teixeira, Yelshin, and Cortez (2006). Additional investigation will highlight fine effects governing HDC in binary mixture packing bed.

Obtained results confirm the above mentioned assumption on the temperature effect on starch separation. It must be pointed out that the amylose-amylopectin peak resolution in the case of Fig. $4 \mathrm{~b}$ is comparable with the resolution obtained with the sizeexclusion chromatographic method (Bello-Pérez, Paredes-López, Roger, \& Colonna, 1996; Bello-Pérez et al., 1998; Carvalho, Zambon, Curvelo, \& Gandini, 2003; Fishman, Rodriguez, \& Chau, 1996; Grant, Ostenson, \& Rayas-Duarte, 2002; Kim \& Willett, 2004; Mua \& Jackson, 1995; Suortti, Gorenstein, \& Roger, 1998; Yokoyama, Renner-Nantz, \& Shoemaker, 1998; Yoo \& Jane, 2002; Zhong, Yokoyama, Wang, \& Shoemaker, 2006). Taking in consideration that in the mixed packing the average channel tortuosity is larger than in the monosize packing (Dias, Teixeira, Mota, \& Yelshin, 2006), the better mixed bed resolution of starch components can be related with the tortuosity.

\section{Conclusions}

The presented results show that HDC in a binary mixture packed bed formed by commercial grade glass beads has the ability to separate amylose and amylopectin at a column temperature of $3{ }^{\circ} \mathrm{C}$. The mixed packing provides a quicker cooling of the mobile phase, a better resolution and a lower pressure drop, when com- pared with the packing containing glass beads with average diameter $5 \mu \mathrm{m}$. The use of unbound glass beads as column packing reduces the equipment costs and may be useful as a fast method to monitor the amylose and amylopectin content of starch samples.

\section{Acknowledgements}

The authors wish to thank FCT for the grant provided to Dr. Alexander Yelshin (Yelshyn). This work was developed under the framework of the project POCI_EQU_58337/2004, partially funded by FEDER.

\section{References}

Bello-Pérez, L. A., Paredes-López, O., Roger, P., \& Colonna, P. (1996). Food Chemistry, $56,171$.

Bello-Pérez, L. A., Roger, P., Baud, B., \& Colonna, P. (1998). Journal of Cereal Science, 27, 267.

Billen, J., Gzil, P., Vervoort, N., Baron, G. V., \& Desmet, G. (2005). Journal of Chromatography A, 1073, 53 .

Błaszczak, W., Fornal, J., Valverde, S., \& Garrido, L. (2005). Carbohydrate Polymers, 61, 132.

Carvalho, A. J. F., Zambon, M. D., Curvelo, A. A. S., \& Gandini, A. (2003). Polymer Degradation and Stability, 79, 133.

Collado, L. S., \& Corke, H. (2003). In G. Kaletunç \& K. J. Breslauer (Eds.), Characterization of cereals and flours: Properties, analysis, and applications. New York: Marcel Dekker.

Churms, S. C. (1996). Journal of Chromatography A, 720, 151.

Dias, R., Teixeira, J. A., Mota, M., \& Yelshin, A. (2004a). Separation and Purification Technology, 37, 69.

Dias, R., Teixeira, J. A., Mota, M., \& Yelshin, A. (2004b). Industrial Engineering and Chemical Research, 43, 7912

Dias, R., Teixeira, J. A., Mota, M., \& Yelshin, A. (2006). Separation and Purification Technology, 51, 180.

Dias, R., Fernandes, C. S., Mota, M., Teixeira, J. A., \& Yelshin, A. (2007). International Journal of Heat and Mass Transfer, 50, 1295.

Durrani, C. M., \& Donald, A. M. (2000). Carbohydrate Polymers, 41, 207.

Eliasson, A.-C. (Ed.) (2004). Starch in food: Structure, function and applications. Cambridge, England: Woodhead Publishing Ltd.

Fang, J. M., Fowler, P. A., Escrig, C., Gonzalez, R., Costa, J. A., \& Chamudis, L. (2005) Carbohydrate Polymers, 60, 39.

Farhat, I. A., \& Blanshard, J. M. V. (2001). In P. Chinachoti \& Y. Vodovotz (Eds.), Bread staling. Boca Raton: CRC Press LLC.

Fishman, M. L., Rodriguez, L., \& Chau, H. K. (1996). Journal of Agricultural and Food Chemistry, 44, 3182

Galinsky, G., \& Burchard, W. (1997). Macromolecules, 30, 6966.

Gidley, M. J., \& Bulpin, P. V. (1989). Macromolecules, 22, 341.

Grant, L. A., Ostenson, A. M., \& Rayas-Duarte, P. (2002). Cereal Chemistry, 79, 771.

Han, J.-A., BeMiller, J. N., Hamaker, B., \& Lim, S.-T. (2003). Cereal Chemistry, 80, 323.

Han, J.-A., \& Lim, S.-T. (2004). Carbohydrate Polymers, 55, 265.

Hanselmann, R., Burchard, W., Ehrat, M., \& Widmer, H. M. (1996). Macromolecules, 29, 3277.

Henshall, A. (2001). In S. S. Cho \& M. L. Dreher (Eds.), Handbook of dietary fiber. New York: Marcel Dekker. 
Kim, S., \& Willett, J. L. (2004). Starch/Stärke, 56, 29.

Klavons, J. A., Dintzis, F. R., \& Millard, M. M. (1997). Cereal Chemistry, 74, 832.

Kobayashi, S., Schwartz, S. J., \& Lineback, D. R. (1985). Journal of Chromatography A, 319, 205.

Kuwahara, F., Shirota, M., \& Nakayama, A. (2001). International Journal of Heat and Mass Transfer, 44, 1153

Matveev, Y. I., van Soest, J. J. G., Nieman, C., Wasserman, L. A., Protserov, V. A. Ezernitskaja, M., et al. (2001). Carbohydrate Polymers, 44, 151.

Mota, M., Teixeira, J. A., \& Yelshin, A. (2001). Transactions of the Filtration Society, 1, 101

Mota, M., Teixeira, J. A., Yelshin, A., \& Cortez, S. (2006). Journal of Chromatography B, 843,63

Mua, J. P., \& Jackson, D. S. (1995). Cereal Chemistry, 72, 508.

Nakazawa, Y., \& Wang, Y.-J. (2003). Carbohydrate Research, 338, 2871
Randzio, S. L., Flis-Kabulska, I., \& Grolier, J.-P. E. (2003). Biomacromolecules, 4, 937. Suknark, K., Phillips, R. D., \& Chinnan, M. S. (1997). Food Research International, 30, 575.

Suortti, T., Gorenstein, M. V., \& Roger, P. (1998). Journal of Chromatography A, 828,

Tako, M., \& Hizukuri, S. (2000). Food Research International, 33, 35.

Vorwerg, W., Radosta, S., \& Leibnitz, E. (2002). Carbohydrate Polymers, 47, 181.

Yang, C., Meng, B., Chen, M., Liu, X., Hua, Y., \& Ni, Z. (2006). Carbohydrate Polymers, 64, 190.

Yokoyama, W., Renner-Nantz, J. J., \& Shoemaker, C. F. (1998). Cereal Chemistry, 75, 530.

Yoo, S.-H., \& Jane, J. (2002). Carbohydrate Polymers, 49, 307.

Zhong, F., Yokoyama, W., Wang, Q., \& Shoemaker, C. F. (2006). Journal of Agricultural and Food Chemistry, 54, 2320. 